$\mathbb{T}$ periodica polytechnica

Civil Engineering

$55 / 2(2011) 129,135$

doi: 10.3311/pp.ci.2011-2.05

web: http://www.pp.bme.hu/ci

(C) Periodica Polytechnica 2011

RESEARCH ARTICLE

\section{Rebound testing of cylindrical spun-cast concrete elements}

\author{
István Völgyi / György Farkas
}

Received 2010-12-07, revised 2011-04-26, accepted 2011-05-17

\begin{abstract}
The aim of the research was to determine the relationship between the Schmidt $N$ rebound index and the compressive strength of spun-cast concrete elements with low water-cement (w/c) ratio. In the research 22 specimens of 8 different mixtures were tested. The investigated mixture parameters included $w / c$ ratio, compaction intensity and type of aggregate. The compressive strength of the concrete in the outer, middle and inner region of the spun-cast element and of the vibrated cube were assessed by testing drilled cores after non-destructive testing of the specimens. Statistical regression functions have been defined for the determination of the relationship between the rebound index and the compressive strength. A special new method has been developed for the quality control of spun-cast concrete elements using a rebound hammer.
\end{abstract}

\section{Keywords}

spun-cast concrete · strength · parametric experimental study $\cdot$ rebound index $\cdot$ quality control

\section{Acknowledgement}

The authors wish to express their gratitude to BVM Épelem $K f t$., SW Umwelttechnik Hungary Kft. for the research materials and for sponsoring the research. Thanks to the Department of Structural Materials and Engineering Geology for their assistance in the laboratory work. Special thanks to Dr. Salem Georges Nehme and Mr András Eipl.

This work is connected to the scientific program of the "Development of quality-oriented and harmonized $R+D+I$ strategy and functional model at BME" project. This project is supported by the New Hungary Development Plan (Project ID: TÁMOP4.2.1/B-09/1/KMR-2010-0002).

\section{István Völgyi}

Budapest University of Technology and Economics, Department of Structural Engineering, H-1111 Budapest, Bertalan L. 2, Hungary

e-mail: volgyi@vbt.bme.hu

\section{György Farkas}

Budapest University of Technology and Economics, Department of Structural Engineering, H-1111 Budapest, Bertalan L. 2, Hungary

e-mail: farkas@vbt.bme.hu

\section{Notation}

c Consistency determined by flow table tests [cm]

$f_{c m}$ Mean value of the modified standard cylinder compressive strength of the specimen [MPa]

$E_{a p p}^{*}$ Modified compacting energy $\left[\mathrm{m}^{2} / \mathrm{sec}\right]$ [enlarged]

$E_{\text {max }}^{*}$ Maximal recommended modified compacting energy $\left[\mathrm{m}^{2} / \mathrm{sec}\right]$ [enlarged]

$E_{\text {need }}^{*}$ Required modified compacting energy $\left[\mathrm{m}^{2} / \mathrm{sec}\right]$ [enlarged]

$P_{e}$ Paste excess $\left[\mathrm{dm}^{3} / \mathrm{m}^{3}\right]$

$\Delta f_{c m}$ Relative cylinder strength variation from the outer to the inner region [\%]

$r_{S}$ Schmidt $\mathrm{N}$ rebound index

\section{Contracted notation}

$X_{c y l}$ Data of standard $150 \times 300 \mathrm{~mm}$ cylinder

$X_{\text {core }}$ Data of $60 \mathrm{~mm}$ diameter drilled core

$X_{\text {in }}$ Data of inner region of the end cross section

$X_{\text {mid }}$ Data of middle region of the end cross section

$X_{\text {out }}$ Data of outer region of the end cross section

$X_{\text {sur }}$ Data of the surface of the spun-cast concrete element

$X_{v i b}$ Data of drilled core from vibrated compacted specimen

\section{Introduction}

Spun-cast concrete poles and piles are typical mass products in several countries. This several decades old technology has lots of advantages such as better protection of reinforcement against corrosion, improved freeze-thaw resistance and resistance against chemical attack.

Spun-casting is an economical method for producing concrete elements with a long tradition. In the mid of the $20^{\text {th }}$ century concrete mixtures were made using high water-cement (w/c) ratios [4]. Excess water left the mixture during centrifugation. 
This way the strength of spun-cast concrete was much higher than the strength of vibrated test cylinders. Spun-cast concrete poles and piles need to have resistance against chemical effects [6]. Today mixtures also need to be made with a low w/c ratio [8]. The low w/c ratio of mixtures is possible with the use of superplasticisers.

Correlations between the strength of the spun-cast and of vibrated elements made of mixtures with low w/c ratio have been published by the authors earlier [16-18]. Due to radial segregation the composition of the material and its strength changes throughout the wall of the element. It has been shown that the composition of the material changes throughout the wall of the specimen due to the radial segregation. The incidence of gravel is higher in the outer region because of its higher density [18]. The result of rebound tests strongly depend on the properties of the microenvironment. Non-destructive testing functions for vibrated concrete [2, 3, 7, 9, 11] are not applicable for spun-cast concrete elements. Standards do not have any special rules for the non-destructive quality control of these products.

Today, the quality control of spun-cast concrete elements is based on testing cylinders or cubes compacted with vibration [7.-9]. Spinning concrete at high speed may cause segregation and different porosities within the concrete wall, which leads to different shrinkage and strength [11]. Previous research by the authors [18] shows that the strength properties of the spun-cast elements significantly depend on the spinning parameters. Quality control using vibrated specimens made of the same mixture is not the best method. This method gives lots of information about the mixture and about the strength of the vibratory compacted concrete, but not enough about the centrifugally compacted product. The geometrical dimensions of the elements (first of all the wall thickness) are usually too small. Usually, quality control using drilled cores is also not possible. Thus the non-destructive quality control of these elements is very important.

The aim of the research was to determine the relationship between the compacting ratio and the manner of segregation, and between cylindrical compressive strength and the rebound index. The aim of the research was also to propose a method for non destructive quality control of these prefabricated elements.

\section{Importance of Non-destructive Test of Spun-Cast Concrete}

On the one hand, material properties of the spun-cast concrete vary in the radial direction. On the other hand, the properties of spun-cast concrete can be very different from vibrated concrete made of the same mixture. The wall thickness of the spun-cast concrete element is often not enough to take drilled material samples from it in the longitudinal or radial direction. Therefore, indirect, non-destructive testing methods are highly important in the case of spun-cast concrete structural elements.

Schmidt rebound hammer testing is a widely used and very important surface hardness testing method for both new rein- forced concrete products and old structures. A large number of functions are available in literature from the last 50 years. Nevertheless, technical literature considering Schmidt rebound hammer testing on special concretes is very limited. An accurate summary of them can be found in [12]. For the rebound method no general theory was developed that can describe the relationship between measured surface hardness and compressive strength. Sometimes the available empirical functions are very different because of the multitude of significant parameters of the relationship between the compressive strength and the measured surface hardness of the concrete materials. The functions are valid only for the special type of concretes of the verification group and of course rebound tests have a larger variability than direct strength tests. Spun-cast concrete has special properties, and special rebound functions are not available for it.

\section{Materials}

Real, normal strength spun-cast concrete mixtures with siliceous aggregate and low water-cement ratio were modeled in the research. Commonly used materials were applied for the mixtures. Rapid cement was applied for the mixtures, which is usual in the case of precast elements. Every mixture in the research contained siliceous aggregate. The grain size distribution of the aggregates was different. Three of the nine mixtures contained crushed gravel. Crushed gravel is also a typical aggregate type in spun-cast concrete elements. The mixtures contained river sand as fine aggregate.

Superplasticiser admixtures were used to improve the natural finish of the concrete. Different types of admixtures were used because of their different secondary effects. Admixtures improve early age strength and decrease the segregation of the mixture. The secondary effect of admixtures is the modification of slump retention. Mixtures named $\mathrm{F}$ and $\mathrm{G}$ were produced in the summer. A superplasticiser with the secondary effect of long slump retention was used for these. Table 1 shows the mixture parameters of the concrete series.

\section{Mixture Parameters}

The superplasticiser was added directly to the mixture after all the other ingredients (cement, aggregates, water). The minimum mixing time was 5 minutes.

The strength of the concrete mixtures and their suitability for producing spun-cast concrete were tested. The mixtures in this series were divided into two main groups, namely: mixtures containing natural gravel aggregate and mixtures containing crushed gravel aggregate.

\section{Experimental Program}

The experimental program consisted of the production and testing of eight series of concrete element segments during a period of approximately six months.

The variables investigated in this test series included spinning speed, spinning duration, type of aggregate, type of cement, 
Tab. 1. Mixture properties

\begin{tabular}{|c|c|c|c|c|c|c|c|c|c|c|c|}
\hline \multirow[t]{2}{*}{ Mixture } & \multirow{2}{*}{$\begin{array}{c}\text { Sand } \\
0-4\end{array}$} & \multicolumn{3}{|c|}{ Silicous gravel } & \multicolumn{2}{|c|}{$\begin{array}{c}\text { Crushed } \\
\text { gravel }\end{array}$} & \multirow[t]{2}{*}{ Cement type } & \multirow[t]{2}{*}{$\begin{array}{c}\text { Cement } \\
{[\mathrm{kg}]}\end{array}$} & \multirow[t]{2}{*}{$\begin{array}{c}\text { Water } \\
{[\mathrm{kg}]}\end{array}$} & \multirow[t]{2}{*}{ Superplasticizer } & \multirow[t]{2}{*}{$\begin{array}{l}\text { Fineness } \\
\text { modulus }\end{array}$} \\
\hline & & $2-8$ & 4-8 & $8-16$ & $0-5$ & $5-12$ & & & & & \\
\hline A & $31,9 \%$ & $25,3 \%$ & & $42,8 \%$ & & & CEM I 42,5 R & 460 & 150 & Glenium C323 mix & 6,20 \\
\hline B & $34,0 \%$ & $25,0 \%$ & & $41,0 \%$ & & & CEM I 42,5 R & 420 & 143 & Glenium C323 mix & 6,35 \\
\hline $\mathrm{C}$ & $32,0 \%$ & $25,0 \%$ & & $43,0 \%$ & & & CEM I 42,5 R & 420 & 143 & Glenium C323 mix & 6,43 \\
\hline D & $19,0 \%$ & & & $32,0 \%$ & $24,0 \%$ & $25,0 \%$ & CEM I $52,5 \mathrm{~N}$ & 400 & 136 & Mapei Dynamon SP1 & 6,30 \\
\hline $\mathbf{E}$ & $43,0 \%$ & & $30,0 \%$ & $27,0 \%$ & & & CEM I $52,5 \mathrm{~N}$ & 420 & 143 & Mapei Dynamon SP1 & 6,03 \\
\hline $\mathbf{F}$ & $40,0 \%$ & & $25,0 \%$ & $35,0 \%$ & & & CEM I $52,5 \mathrm{~N}$ & 420 & 143 & Mapei Dynamon SR3 & 6,55 \\
\hline G & $50,0 \%$ & & $10,0 \%$ & & & $40,0 \%$ & CEM I $52,5 \mathrm{~N}$ & 460 & 138 & Mapei Dynamon SR3 & 6,06 \\
\hline $\mathbf{I}$ & $45,0 \%$ & & $25,0 \%$ & $30,0 \%$ & & & CEM I $52,5 \mathrm{~N}$ & 495 & 150 & Stabiment FM 95E & 6,00 \\
\hline
\end{tabular}

amount of cement, and water-cement ratio.

Segments with $200 \mathrm{~mm}$ length, $500 \mathrm{~mm}$ diameter and 130$190 \mathrm{~mm}$ wall thickness were produced on the spinning machines of the companies for each mixture to examine compressive strength. $\varnothing 150 / 300 \mathrm{~mm}$ vibrated control cylinders were produced too.

Forms for two identical specimens were filled, and lifted to the spinning machine. An individual spinning program for each specimen was run. During the spinning procedure the consistency of the fresh mixture was determined by flow table tests, and standard control cylinders and cubes were produced. The specimens were left in the form for 24 hours. Vibrated control elements were stored under water for 7 days and in the laboratory for additional 21 days.

After 28 days, rebound tests were carried out on the end cross section region, on the surface of the spun-cast element and on the vibrated control specimen using a Schmidt N rebound hammer. Rebound tests were carried out following the rules of Proceq [12] and EN 13791 [7]. $60 \mathrm{~mm}$ diameter cores (height $85-95 \mathrm{~mm}$ ) were drilled from the outer, middle and inner regions of the specimens and from the vibratory compacted control specimens (Fig. 1). Four test cores were made from each end cross section region of each specimen. The mean value of the compressive strength of the cores and of the reference standard $\varnothing 150 / 300 \mathrm{~mm}$ specimens was determined. The test was accomplished according to EN 125041 [5]. 424 destructive compression strength tests were made.
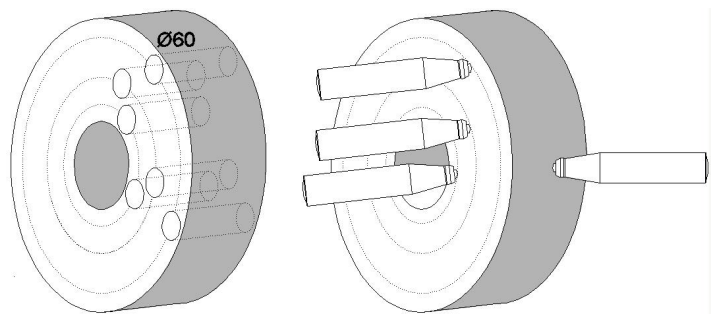

Fig. 1. Place of destructive and nondestructive tests

\section{Short Summary of the Destructive Tests}

The experimental program included destructive tests of spuncast concrete specimens. Non-destructive experimental test results are based on the results of the destructive tests. A short summary is given below.

The specimens were divided into five compression classes from the too low applied compaction to the too high applied compaction. Strength properties of specimens are various according to the applied compression energy. Applied enlarged compaction energy is a production of the pressure at the outer radius of the specimen caused by the centrifugal effect and the compaction time. Compression classes have been defined in [18] after the applied compaction energy. The cylindrical compressive strength of concrete was determined using drilled cores from the inner, middle and outer region of spuncast specimen and from the vibratory compacted specimens (Table 2). A polynomial regression function was determined for the $f_{c m, \text { out }} / f_{c m, v i b}$ ratio and for the $\Delta f_{c m}=\left(f_{c m, o u t}-\right.$ $\left.f_{c m, \text { in }}\right) / f_{c m, \text { out }}$ ratio, as function of the $E *$ app $/ E *_{\text {need }}$ ratio and paste excess [15]. See more about this topic in [18]. The functions are shown in Fig. 2 and Fig. 3 .

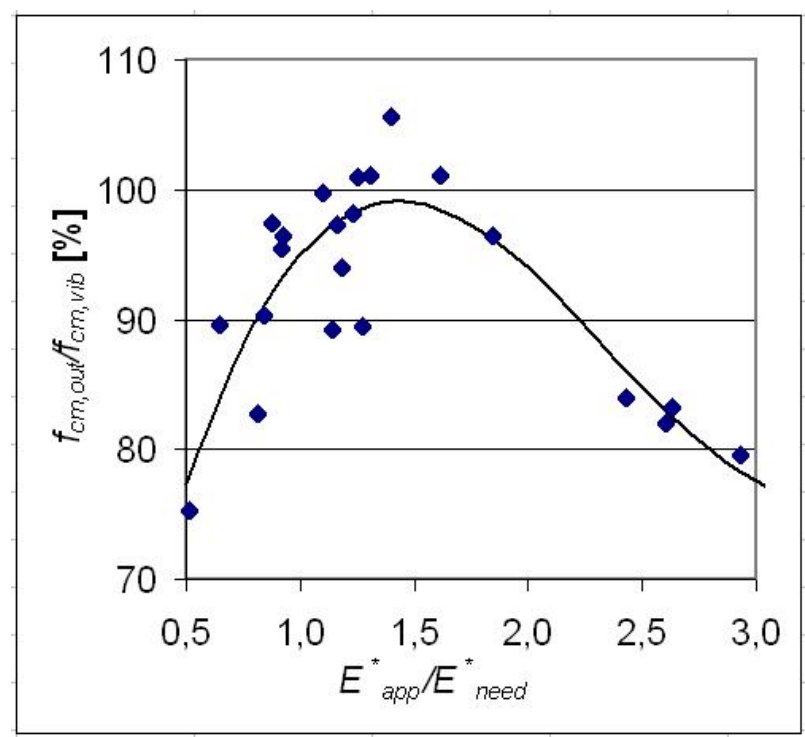

Fig. 2. Measured relative compressive strength of the outer region vs. relative compaction energy and regressed relative compressive strength function vs. relative compaction energy

\section{Nondestructive Test Method and Test Results}

Rebound tests using a Schmidt N hammer following [12] were carried out on the spun-cast specimens and on the vibrated cubes made of the mixtures listed in Table 1 . The inner, middle 
Tab. 2. Summary of parameters and results

\begin{tabular}{|c|c|c|c|c|c|c|c|c|c|c|c|c|c|c|}
\hline & & & & & & & & & & & Mean & test & alues & \\
\hline $\begin{array}{l}\stackrel{d}{E} \\
\stackrel{D}{Z} \\
\end{array}$ & 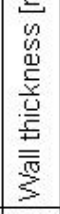 & 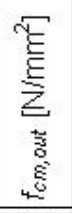 & 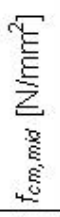 & 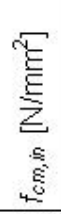 & 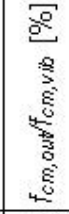 & 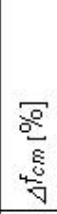 & 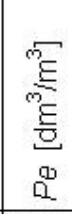 & 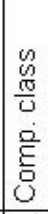 & 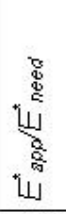 & $\begin{array}{r}9 \\
\overrightarrow{5} \\
0\end{array}$ & $\begin{array}{c}\subseteq \\
b \\
\stackrel{6}{L}\end{array}$ & $\begin{array}{c}\text { है } \\
\text { है } \\
\text { b- }\end{array}$ & 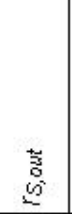 & 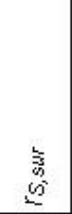 \\
\hline $\mathrm{A} / 1$ & 185 & 47,2 & 49,4 & 65,8 & 79 & 31,3 & 100,8 & 5 & 2,9 & 40,5 & 50,0 & 48,8 & 43,7 & 56,7 \\
\hline $\mathrm{A} / 2$ & 127 & 49,4 & 53,5 & 60,7 & 83 & 18,9 & 100,8 & 4 & 2,6 & 40,5 & 49,7 & 47,6 & 43,9 & 54,5 \\
\hline $\mathrm{A} / 3$ & 185 & 53,1 & 54,3 & 56,4 & 89 & 5,5 & 100,8 & 3 & 1,3 & 40,5 & 47,3 & 46,6 & 45,4 & 49,8 \\
\hline$\sqrt{4}$ & 127 & 53,0 & 55,9 & 53,8 & 89 & 1,3 & 100,8 & 3 & 1,1 & 40,5 & 45,3 & 44,8 & 43,6 & 45,5 \\
\hline $8 / 1$ & 163 & 51,3 & 56,2 & 61,6 & 93 & 18, & 104,0 & 3 & 1,2 & 45,0 & 49,9 & 47,5 & 45,9 & 54,2 \\
\hline $\mathrm{B} / 2$ & 129 & 54,5 & 57,4 & 61,6 & 99, & 7, & 104,8 & 3 & 1,1 & 45,0 & 48,4 & 45,2 & 44,9 & 51,1 \\
\hline $\mathrm{B} / 3$ & 173 & 52,1 & 54,9 & 57,5 & 95 & 9,8 & 104,8 & 3 & 0,9 & 45,0 & 48,6 & 47,1 & 46,1 & 53,6 \\
\hline$B / 4$ & 131 & 49,3 & 55,3 & 62,2 & 90 & 23, & 104,9 & 3 & 0,8 & 45,0 & 49,4 & 47,8 & 45,2 & 52,7 \\
\hline $\mathrm{Cl} 1$ & 157 & 53,5 & 58,5 & 62,0 & 96 & 15, & 100,2 & 3 & 0,9 & 45,5 & 49,7 & 46,4 & 44,6 & 52,8 \\
\hline $\mathrm{C} / 2$ & 134 & 54,0 & 63,6 & 62,5 & 97 & 15, & 100,2 & 3 & 0,9 & 47,2 & 46,9 & 46,5 & 45,2 & 52,1 \\
\hline $\mathrm{C} / 3$ & 155 & 56,0 & 61,2 & 64,3 & 101. & 15, & 100,2 & 7 & 1,3 & 47,2 & 50,8 & 48,5 & 45,4 & 51,9 \\
\hline $\mathrm{C} / 4$ & 125 & 54,0 & 57,3 & 60,8 & 97. & 12, & 100,2 & 3 & 1,2 & 47,2 & 52,0 & 46,5 & 44,9 & 52,8 \\
\hline $\mathrm{D} / 1$ & 151 & 58,4 & 65,5 & 70,7 & 89 & 18, & 75,2 & 4 & 0,6 & 52,0 & 52,9 & 56,5 & 53,8 & 51,3 \\
\hline $\mathrm{D} / 2$ & 123 & 68,9 & 69,1 & 71,8 & 105 & 4,8 & 75,2 & 3 & 1,4 & 52,0 & 55,7 & 55,4 & 53,6 & 57,9 \\
\hline$E / 1$ & 140 & 44,7 & 52,6 & 53,8 & 96 & 197 & 83,0 & 4 & 1,8 & 47,5 & 53,9 & 49,2 & 42,5 & 56,1 \\
\hline $\mathrm{E} / 2$ & 149 & 45,5 & 48,7 & 50,8 & 98 & 11. & 83, & 4 & 1,2 & 47,5 & 53,7 & 52,0 & 46,1 & 54,7 \\
\hline$F / 1$ & 124 & 57,0 & 58,9 & 61,1 & 101. & 7,2 & 89.4 & 3 & 1,6 & 49,4 & 56,8 & 54,4 & 54,0 & 57,2 \\
\hline $\mathrm{F} / 2$ & 125 & 42,5 & 44,4 & 47,6 & 75 & 9,1 & 89.4 & & 0,5 & 49,4 & 48,7 & 51,7 & 49,6 & 48,3 \\
\hline $\mathrm{G} / 1$ & 151 & 58,2 & 63,5 & 64,4 & 101. & 10,8 & 76,6 & & 1,3 & 48,7 & 56,2 & 56,9 & 55,6 & 56,1 \\
\hline $\mathrm{G} / 2$ & 150 & 47,6 & 50,8 & 52,7 & 82 & 8,8 & 76,6 & & 0,8 & 48,7 & 49,0 & 52,3 & 50,5 & 49,2 \\
\hline$/ 1$ & 178 & 39,4 & 30,8 & 28,5 & 77 , & 30,0 & 114,7 & & 3,4 & 43,1 & 56,1 & 54,8 & 45,5 & 58,0 \\
\hline $1 / 2$ & 148 & 59,9 & 68,4 & 62,9 & 82, & 26,0 & 114,7 & 4 & 2,6 & 45,6 & 54,5 & 53,4 & 51,4 & 55,8 \\
\hline
\end{tabular}

and outer region of the cross section and the outer surface were tested. No rebound test was made in the $20 \mathrm{~mm}$ wide border region of the surface.

Four series of rebound test from each region were carried out. There were 20 tests in each series. The quantity of reading is able to improve the accuracy of the mean rebound number to $5 \%$ [1]. The mean value of the readings is assigned to the compressive strength of the drilled core. The pairs of compressive strength measured using drilled cores and rebound indices of horizontal tests and three rebound functions [3, 7, 9] often used in Hungary are shown in Fig. 4.

\section{Specialities of Schmidt Rebound Test of Spun-Cast Concrete Elements}

The viscosity of the concrete mixture is relatively high. This internal friction affects lower compacting pressure in the secondary (longitudinal) direction than in the radial one. Therefore, the material properties of spun-cast concrete are also directional. This effect is not typical for spun-cast concrete. This was shown earlier by Nehme for vibratory compacted high strength concrete mixtures [10].

It is well known that segregation of the mixture causes different composition along the radius. This will cause different mechanical properties, Young's modulus, strength, shrinkage, etc. of the concrete. Strength and rebound number are different near the worked surface of vibratory compacted specimens, too. Centrifugal compaction results in an outer region of the

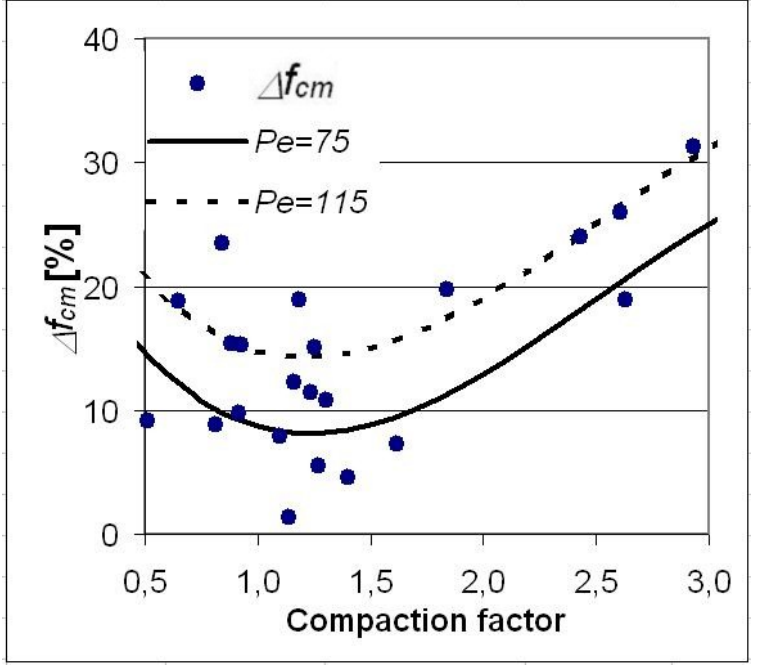

Fig. 3. Measured relative compressive strength variation in the wall of the element vs. relative compaction energy and values of the regression function vs. relative compaction energy ( $2 \mathrm{D}$ section)

wall rich in aggregate. The inner region is rich on cement paste, which leads to different porosity of the material. The rebound number of concrete depends on the microenvironment of the test point and on the porosity of the concrete [14]. Energy losses due to dissipation by concrete crushing under the tip of the plunger vary.

Rebound testing is an indirect method. Also, it is clear that the valid rebound function is different for the surface and for the different cross section regions. Sometimes, primarily in case of 
installed elements, carrying out rebound testing is only possible on the outer surface. Therefore, test results along the cross section which are reported here may give useful additional information.

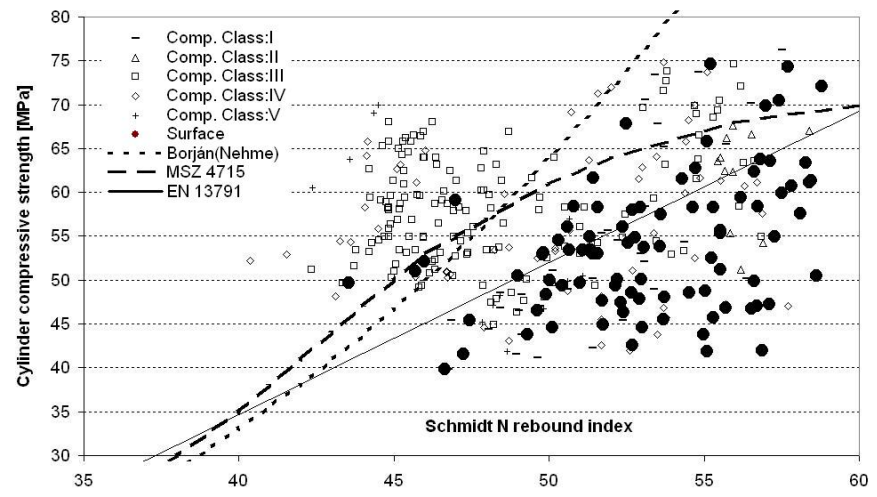

Fig. 4. Cylindrical compressive strength of the cross section of the spuncast concrete elements to Schmidt rebound index according to the compaction classes. Cylindrical compressive strength of the outer region of the cross section to Schmidt rebound index of the surface. Rebound functions from technical literature.

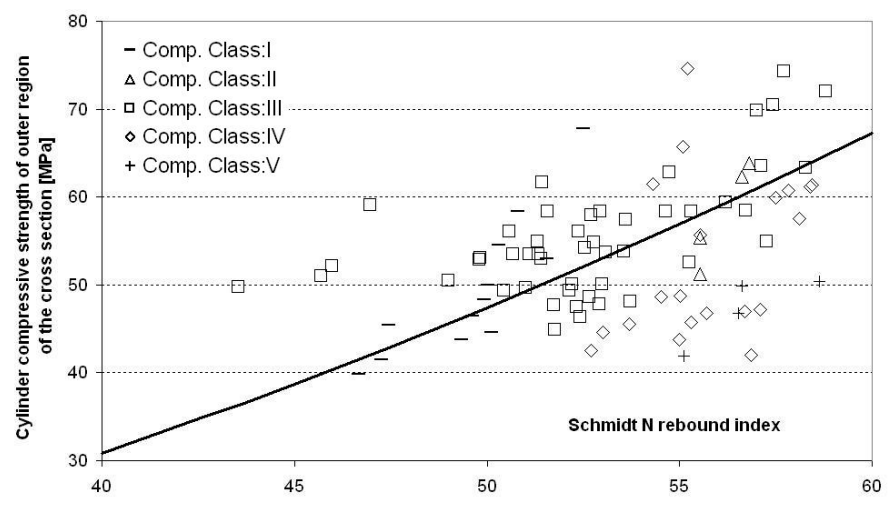

Fig. 5. Rebound test result taken on the surface and proposed rebound function for approximation of the mean compressive strength of spun-cast concrete (equation (1)).

\section{Analysis of Rebound Test Results}

The functions proposed in [3,7] and [9] (Fig. 3] are determined for lower strength concrete materials. Their functions are extrapolated for high strength concrete. It was verified earlier by Nehme [11] that the function in [3] is suitable for high strength concrete only after correction. The figure shows that the function given in [3] (modified after Nehme), transformed to a $150 \mathrm{~mm}$ diameter cylinder, and the functions given in [7] and [9] overestimate the cylindrical strength significantly.

Application of non-destructive rebound testing on the surface of real products is always possible, but the end cross section of installed elements is often too small or not available. That is why the function proposed for estimation of the concrete strength of the extreme outer region utilizes only the rebound results of the surface. Fig. 5 shows the rebound indices measured on the surface of the spun-cast concrete elements.

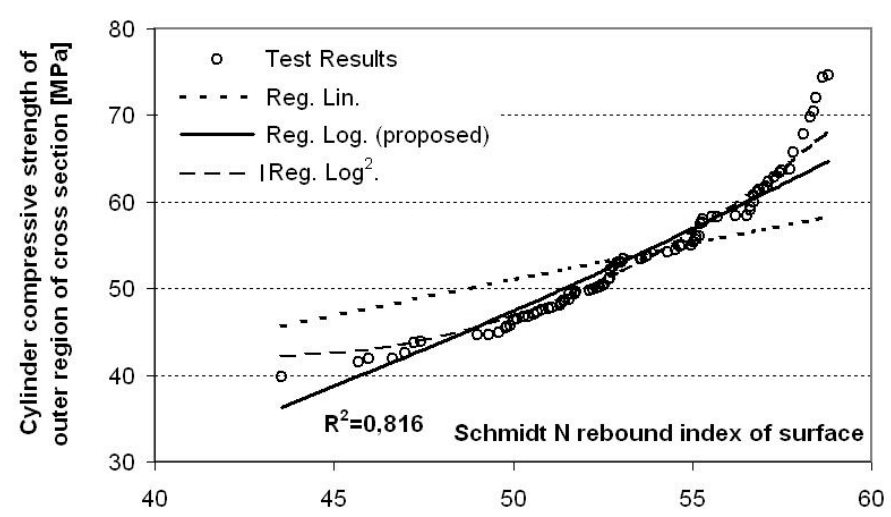

Fig. 6. Quantile curve of the rebound test result of the surface. Shape of the linear regression function of the direct test result. Shape of the second order log$\log$ regression function of the quantile curve. Shape of the proposed first order $\log$-log regression rebound function of the quantile curve.

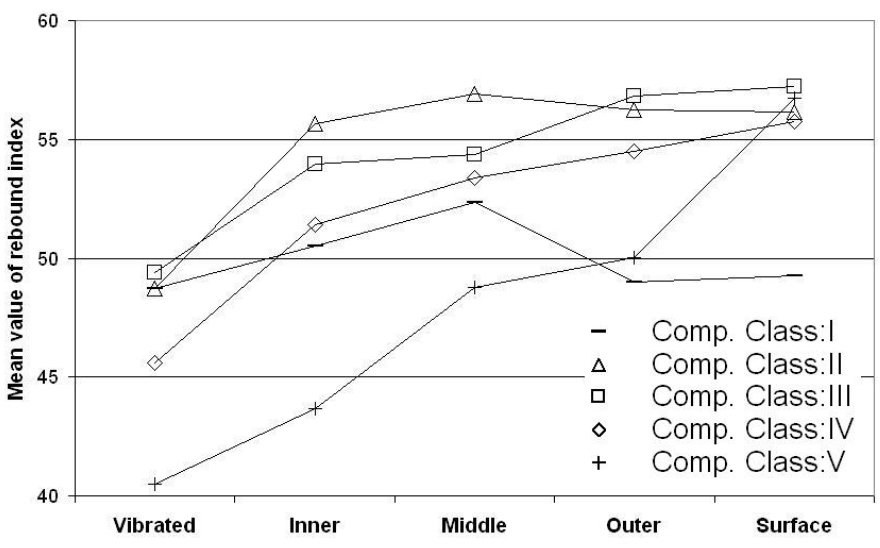

Fig. 7. Individual tendency of the rebound results in the different compaction classes

Both the measured cylindrical strength of the drilled core and therebound index are random variable. The Reimann quantile curve is the best method for analysis of random variables [13]. Fig. 6 shows the quantile curve.

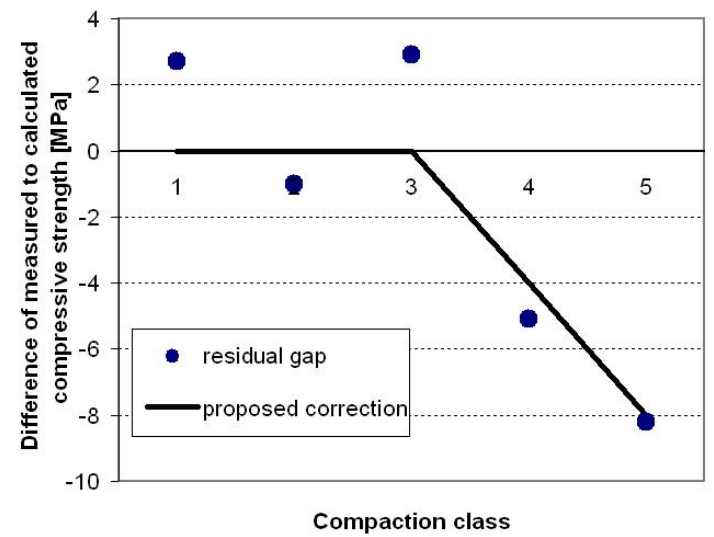

Fig. 8. Residual differences between the mean value of the calculated and the measured compressive strength of the spun cast concrete specimens, and proposed correction according to the compaction class.

Several types (linear, exponential, polynomial) of regression functions were checked (Fig. 5). The regression functions were evaluated from the point of view the residual variation and the 
shape of the function. The proposed function gives a relatively low residual variation and has a conventional slightly curved shape in the lower rebound index region too. The proposed formula is as follows:

$$
f_{\text {cm, out }}=10^{-1,59+1,92 \cdot \log \left(R_{\text {sur }}\right)} \quad 40 \leq r_{s, \text { sur }} \leq 60
$$

Formula 1 is valid for normal strength spun-cast concrete with w/c ratio of 0,3 - 0,35 and siliceous aggregate. Fig. 4 shows that that connection between rebound index and cylinder compressive strength is very different for different compression classes. The problem of this simplified method is that does not use the information of the compression class.

In case size and position of the end cross section of the element is able for non destructive test, we have chance to have this information. It was shown in chapter 6 that variation of material properties in the wall is different if the compaction class changes. Rebound data on the end cross section, on the surface and on the vibrated specimens are suitable for determination of the compaction class [18] of the element. Using this data approximation of $\Delta f_{c m}=\left(f_{c m, \text { out }}-f_{c m, \text { in }}\right) / f_{c m, \text { out }}$ ratio is possible. See Fig. 2 .

One characteristic specimen of each class was chosen. Fig. 7 shows the mean values of the rebound indices of the vibrated specimen, the inner, middle and outer cross section regions and of the surface.

The trend of the rebound indices shows impact of the compaction class of the specimen. The typical trend is that the rebound index measured on the surface of the spun-cast specimen is always higher than the value measured on the vibrated specimen. The characteristics of the specimens from the special compaction classes are as follows:

- Compaction class I (very low compaction): Rebound index of the outer region and of the surface decreases hard

$\left(\mathrm{r}_{S, \text { mid }}-\mathrm{r}_{S, \text { sur }}\right)>3$

- Compaction class II (low compaction): Rebound index of the outer region and of the surface decreases strongly.

$3>\left(\mathrm{r}_{S, \text { mid }}-\mathrm{r}_{S, \text { sur }}\right)>0$

- Compaction class III (normal compaction): Rebound index increases monotonically from the vibrated data to the surface. The increment is moderate in the outer region.

- Compaction class IV (high compaction): Rebound index increases monotonically and significantly from the inner region to the surface. $\left(\mathrm{r}_{S, \text { sur }}-\mathrm{r}_{S, \text { in }}\right)>3$

- Compaction class V (very high compaction): Rebound index of the outer region and of the surface increases strongly

$\left(\mathrm{r}_{S, \text { sur }}-\mathrm{r}_{S, \text { out }}\right)>3$

The rebound index of the outer region and of the surface basically depends on the compaction factor of the specimen. The connection between the compaction class and the rebound index of the inner and middle region is more variable. The background of this effect is as follows. The composition of the inner region depends remarkably on paste excess. The inner region of specimens made of mixture with high paste excess and with high compaction may have a total lack of gravel. This can cause lower rebound index in the inner region.

If spinning parameters of the specimen are lacking, approximation of the compressive strength of the inner region of the end cross section is possible using the rebound information of the end cross section. The proposed method is as follows:

- determination of the compaction class of the specimen using the rebound indexes of the end cross section;

- taking the compaction factor as 0,5 multiplied by the number of the compaction class;

- using the real paste excess after Újhelyi in case it is known, choose $P e=75$ otherwise;

- approximation of the value of $\Delta f_{c m}$ ratio is possible according to [18].

Fig. 7 show the analysis of the residual differences between the mean value of the calculated and the measured compressive strength of the spun cast concrete specimens. Proposed formula is conservative if compaction of specimen is not higher than needed. In case of overcompaction formula (1) is nonconservative. In case of quality control correction is also needed. Fig. 8 show the proposed correction of the authors. Compressive strength calculated after formula (1) should be reduced by $4 \mathrm{MPa}$ in case compaction class is IV and by $8 \mathrm{MPa}$ in case compaction class is $\mathrm{V}$.

If information about compaction class is lacking it is proposed to use the reduction of class 5 . in case of quality control.

\section{Conclusions}

Conclusions for the mixtures of the research are as follows.

Segregation of concrete mixture during spun-casting depends significantly on the paste excess and on the compacting ratio. Properties like strength, porosity, hardness and composition vary throughout the wall of the spun-cast concrete elements due to the mixture segregation.

Quality testing and strength approximation of spun-cast concrete elements are possible using Schmidt hammer.

Rebound index vs. cylindrical compressive strength functions calibrated to vibratory compacted concrete materials are on the unsafe side in the case of spun-cast concrete materials.

Rebound index vs. cylindrical compressive strength functions were calibrated to spun-cast concrete materials using 22 specimens with low water-cement ratio and siliceous aggregate.

A new method has been determined for the approximation of the variation of compressive strength from the outer region to the inner region of spun-cast concrete elements using the rebound indices measured on the cross section of the element.

After analysis of the residual differences between the calculated and measured compressive strength of specimens a correction function has been defined as a function of the compression class. 


\section{References}

1 Arni H P, Impact and Penetration Tests of Portland Cement Concrete, Highway Research Record 378, Highway Research Board, Washington D.C, 1972.

2 Balázs G, Borján J, Horváth A, Schwerteczky F, Effect of inhomogenity on strength and deformation characteristics of concrete, Periodica Polytechnica Civil Engineering 37 (1993), no. 4, 313-320.

3 Borján J, Non-destructive concrete tests, Múszaki Könyvkiadó, Budapest, 1981.

4 Csutor J, Compaction of concrete, Múegyetemi Kiadó, Budapest, 1967.

5 EN 12504-1:2001 Testing concrete in structures. Part 1.

6 EN 12843:2005 Precast concrete products. Masts and poles.

7 EN 13791:2007 Assessment of in-situ compressive strength in structures and precast concrete.

8 EN 1992-1-1:2010 Design of concrete structure. Part 1-1: General rules and rules for buildings.

9 MSZ 4715-5:1972 Testing of hardened concrete. Non-destructive testing.

10 Nehme S G, Balázs L G, Effect of porosity on the properties of concrete, Concrete Structures 4 (2003), 72-75.

11 Nehme S G, The Porosity of Concrete, PhD thesis, BME, Hungary, 2004.

12 Non-destructive testing of concrete - Schmidt concrete test hammer, Proceq SA, address $=$ Switzerland, date $=2005$.

13 Reimann J, V Nagy I, Hydrology statistics, Tankönyvkiadó, Budapest, 1984.

14 Szilágyi K, Borosnyói A, 50 years of experience with the Schmidt rebound hammer, Concrete Structures 10 (2009), 46-56.

15 Ujhelyi J, Concrete sciences, Múegyetemi Kiadó, Budapest, 2005.

16 Völgyi I, Farkas Gy, Concrete technological and structural problems of spun-cast concrete elements, ÉPKO 2009 (Csíksomlyó).

17 _ Determination of strength of spun-cast concrete elements, Fifth International PhD \& DLA Symposium in Engineering (Pécs, 2009).

18 Völgyi I, Farkas G, Nehme S G, Concrete Strength Tendency in the Wall of Cylindrical Spun-Cast Concrete Elements, Periodica Polytechnica Civil Engineering 54 (2010), no. 1, 23-30. 